\title{
Study on the Impact of Urban Residents' Information Consumption Structure Changes on Information Consumption Industry in Liaoning Province
}

\author{
Jie Xiao * \\ School of Management \\ Dalian Polytechnic University \\ Dalian, China
}

\author{
Xiaonan Fan \\ School of Management \\ Dalian Polytechnic University \\ Dalian, China
}

\begin{abstract}
This paper first expounds the the ory of the impact of information consumption on the information consumption industry, analyzes the three factors that affect information consumption, and demonstrates the general law of the impact of information consumption on the information industry. Secondly, the data of information consumption in Liaoning Province in recent years is compiled, and the content of information consumption is analyzed through data analysis. Then the information consumption data is divided into four categories into the ELES model to calculate the information consumption under different consumption categories. The coefficient of elasticity is used to analyze the law of changes in consumption structure in Liaoning Province. According to the input-output model, the composition of information industry is analyzed, and the information industry is divided into three categories. The influence coefficient and the induction coefficient are used to quantitatively analyze the structural changes of the information industry. Finally, through the above analysis results, we will make a simple countermeasure analys is for the information industry, and provide reference for the government and other relevant units to formulate policies for the stimulation of information consumption and the transformation and upgrading of the information industry.
\end{abstract}

Keywords_-Information Consumption; Consumption Structure; ELES Model; Input-Output Model

\section{INTRODUCTION}

With the advancement of information technology, information consumption has developed from the professional field to the general public. Consumers' expenditure on information consumption has gradually evolved from simple use of telephone and web surfing to Internet finance and online education and some new types of information consumption, such as web doctors and mobile clients. In general, information consumption has covered the daily life of the entire social residents, and the information consumption structure has been constantly changing with the development of information technology, and this change has also promoted the development of the information industry. The ever-changing consumption of residents' information requires constantly researching in this area. At the same time, the changes in information consumption structure affect the development direction of the information industry. The upgrading and development of the information industry has a self-evident significance for the economic acceleration and stability of Liaoning Province.

\section{THE DEFINITION OF INFORMATION CONSUMPTION AND THE COMPOSITION OF INFORMATION CONSUMPTION}

\section{A. The definition of information consumption}

Due to the different perspectives of scholars and institutions, there has not a universally accepted definition of the true meaning of information consumption, and no unified authoritative interpretation has been formed among countries. Based on the summary of predecessors' theory, the author believes that the definition of information consumption should include the following aspects. First, the content of information consumption is a product or service that directly meets consumers' demand for information. Second, it must be reflected in the consumption of material wealth. Third, information consumption reflects the consumer's spiritual needs. Therefore, the definition of information consumption in this paper is: information consumption refers to the behavior and process of information consumers purchasing information products and services in order to satisfy their direct demand for information, and consumers satisfy their own spiritual needs by consuming material wealth.

\section{B. The composition of information consumption}

According to the definition of information consumption, the composition of information consumption mainly includes three aspects: information consumption environment, information consumption subject and information consumption object [1].

The information consumption environment mainly refers to the economic and policy environment of information consumption, which is an objective factor affecting information consumption. The development of information consumption requires a certain economic foundation and requires the support of national policies. The main body of information consumption refers to the decision makers and initiators of information consumption activities, that is, what we usually 
call consumers. From the perspective of the buyer's attributes, the information consumer can be divided into individual consumers and organizational consumers (enterprises, institutions, organizations, etc.). The object of information consumption refers to various information products and services in the market, mainly covering education, entertainment, medical care, science and technology and so on.

\section{ANALYSIS OF FACTORS AFFECTING INFORMATION CONSUMPTION}

Resident information consumption is a dominant form of consumption in the information society, where people are driven by interests. In the process of consumption, information consumption is mainly affected by three structural factors: information consumption subject and information consumption object and information consumption environment [2].

\section{A. Analysis of information consumption subject}

Information consumption subject, that is, the information consumer is the dominator of information, and its impact on information consumption mainly comes from the following three aspects[3].

First is the influence of information consumers themselves, such as the income level of residents, disposable income, age, education, social status, and work situation. The income level of residents and the amount of disposable income will directly affect the choice of information consumers for information industry and facilities. Similarly, information consumption requires the matching of information industry and facilities.

Second is information consumer's information quality ability. Information quality factors affecting information consumption mainly include information cognitive ability, information technology ability and information acquisition and use ability. In general, the stronger the consumer's information cognition ability, the deeper the understanding of the role of information, the greater the demand for information consumption, and the higher the level of information consumption.

Third is information consumer's subjective factor, such as values, information consumption habits, etc. The consumption of information consumers has irreversible characteristics. The information consumption behavior of information consumers in the early stage will affect their subsequent consumption behaviors. The information consumption level will not fall immediately due to the decline of current income. Therefore, information consumption's irreversible characteristics have an important influence on future information consumption level.

\section{B. Analysis of information consumption object}

Information consumption object is the core of consumers' purchase behavior. Therefore, the difference of information products and services will have a certain impact on consumers' information consumption. The factors affecting the object of information consumption mainly consist of three aspects: the utility of information products, the development level of information industry and the level of technological development.
Information utility refers to the utility that information products and services can bring to consumers. The utility of information products comes from the use value of information products, that is, the degree to which consumers' information needs are satisfied by consuming and using information goods. The development level of information industry directly determines the content of information and the price and quality of information software. Generally, the higher the development level of the information industry, the lower the price, the more variety and the better the quality of related information products and services, and the better the classification and filtering management of related information content. The development of information technology will certainly promote the development of the information industry, enrich information tools and information content, speed up the speed of its upgrading, and promote the reduction of information products prices, thereby promoting information consumption.

\section{Analysis of information consumption environment}

The information consumption environment refers to the sum of all social and natural factors related to human information activities. On the one hand, information consumption is affected and restricted by the information consumption environment. On the other hand, it influences and changes the information consumption environment through its own initiative and creativity. A good consumer environment is a powerful guarantee for resident consumption information, which is conducive to the construction of sustainable consumption methods and can promote the improvement of information consumption. Information policies and laws and regulations can regulate the problems in information consumption and guide the information consumption environment to a healthy and orderly direction.

\section{ANAlysis on the Change TREND OF Residents' INFORMATION CONSUMPTION STRUCTURE}

According to the statistical yearbook of Liaoning Province, all the information consumption data of Liaoning Province from 2007 to 2016 were sorted out, and the main changes of residents' information consumption in Liaoning Province were analyzed by ELES model, and the laws of changes of information consumption structure in Liaoning Province in the past ten years were calculated.

\section{A. Analysis on the Change of Information Consumption}

Structure of Urban Residents in Liaoning Province

The information consumption of residents in Liaoning Province began to sprout in the 1990s. After nearly 20 years of development, the scale of information consumption and the content form of information consumption have become more diversified. The paper intercepts the time period in which information consumption changes are most representative, that is, the interval from 2007 to 2016.

According to the Statistical Yearbook of Liaoning Province, it was found that the urban residents' information consumption products changed greatly from 2007 to 2016. The information consumption structure was affected by the technical level and industrial structure. From the one-way information transmission channels such as books, magazines, newspapers, radio and television, to the two-way, instant information 
interactive communication such as mobile phones, the Internet and mobile clients, information consumption of urban residents in Liaoning Province is enriched by the continuous development of information technology and information industry. At the same time, changes in residents' information consumption promote the continuous optimization of the consumption structure. The proportion of information consumption to total consumption expenditure reflects the consumption structure of urban residents in Liaoning Province, and this change in proportion also represents the changing pattern of information consumption structure, as shown in Table 1.

TABLE I. THE COMPOSITION OF URBAN RESIDENT S' INFORMATION CONSUMPTION EXPENDITURE

\begin{tabular}{|c|c|c|c|}
\hline Year & $\begin{array}{c}\text { Communication } \\
\text { consumption } \\
\text { expenditure } \\
\text { accounts for total } \\
\text { expenditure on } \\
\text { consumption }\end{array}$ & $\begin{array}{c}\text { Educational } \\
\text { consumption } \\
\text { expenditure } \\
\text { accounts for total } \\
\text { expenditure on } \\
\text { consumption }\end{array}$ & $\begin{array}{c}\text { Cultural and } \\
\text { entertainment } \\
\text { consumption } \\
\text { expenditure accounts } \\
\text { for total expenditure on } \\
\text { consumption }\end{array}$ \\
\hline 2007 & $5.80 \%$ & $6.46 \%$ & $3.08 \%$ \\
\hline 2008 & $5.48 \%$ & $5.97 \%$ & $2.56 \%$ \\
\hline 2009 & $4.72 \%$ & $5.96 \%$ & $2.54 \%$ \\
\hline 2010 & $5.20 \%$ & $5.50 \%$ & $2.60 \%$ \\
\hline 2011 & $4.86 \%$ & $5.12 \%$ & $2.68 \%$ \\
\hline 2012 & $4.92 \%$ & $4.92 \%$ & $2.63 \%$ \\
\hline 2013 & $5.42 \%$ & $6.94 \%$ & $2.33 \%$ \\
\hline 2014 & $4.43 \%$ & $5.72 \%$ & $5.37 \%$ \\
\hline 2015 & $4.79 \%$ & $5.87 \%$ & $5.35 \%$ \\
\hline 2016 & $4.50 \%$ & $6.71 \%$ & $5.36 \%$ \\
\hline
\end{tabular}

B. The ELES Model of Information Consumption Structure of Urban Residents in Liaoning Province

The ELES model has been widely used in the study of consumption and consumption structure by its concise equation form. In this paper, the basic conditions of the extended linear model are satisfied to make a basic linear analysis of information consumption, and the elastic coefficient of each information consumption is calculated and the consumption propensity of information consumption is analyzed [4].

The basic expression of the ELES model is as follows:

$$
M_{i}=T_{i} X_{i}+\beta_{i}\left(Y-\sum_{i=1}^{n} T_{i} X_{i}\right)
$$

In the formula, $M$ represents the consumption expenditure of the consumer for the i-th commodity or service; Y represents the disposable income of the consumer; Ti represents the market price of the i-th commodity or service; and $\mathrm{Xi}$ represents the basic demand for the i-th commodity or service; $\beta \mathrm{i}$ represents the marginal budget share of the i-th commodity and labor. TiXi is the amount of basic demand for the i-th commodity or service, $\sum_{i=1}^{n} T_{i} X_{i}$ is the total amount of expenditure for the basic demand.

Make appropriate changes to the model:

$$
M_{i}=A_{i}+\beta_{i} Y, A_{i}=T_{i} X_{i}-\beta_{i} \sum_{i=1}^{n} T_{i} X_{i}
$$

Linear regression can be used to derive estimates of $\mathrm{A}$ and $\beta \mathrm{i}$

In this paper, $\mathrm{M}$ represents the amount of consumption expenditure of each type of consumption of urban residents. Urban residents' information consumption is divided into three categories, namely, communication consumption expenditure, education consumption expenditure, cultural and entertainment consumption expenditure. $\mathrm{Y}$ represents per capita annual disposable income [5].

According to the statistics of urban consumption statistics of Liaoning Province from 2007 to 2016, the data of each consumption category was compiled, and the data was brought into SPSS to obtain the information consumption function. The analysis results are shown in Table 2 .

TABLE II. INFORMATION CONSUMPTION FUNCTION

\begin{tabular}{|c|c|c|c|}
\hline & $\mathbf{A i}$ & $\boldsymbol{\beta i}$ & $\mathbf{R}^{2}$ \\
\hline $\begin{array}{c}\text { communication consumption } \\
\text { expenditure }\end{array}$ & 201.084 & 0.027 & 0.947 \\
\hline $\begin{array}{c}\text { education consumption } \\
\text { expenditure }\end{array}$ & -22.645 & 0.045 & 0.853 \\
\hline $\begin{array}{c}\text { cultural and entertainment } \\
\text { consumption expenditure }\end{array}$ & -44.346 & 0.041 & 0.95 \\
\hline
\end{tabular}

Communication consumption expenditure model:

$\mathrm{M}=201.084+0.027 \mathrm{Y}$

Education consumption expenditure model:

$\mathrm{M}=-22.645+0.045 \mathrm{Y}$

Cultural and entertainment consumption expenditure model:

$\mathrm{M}=-44.346+0.041 \mathrm{Y}$

The Sig values of the above equations and parameters are all below 0.05 , so the model is established.

1) Analysis of residents' marginal consumption propensity

The marginal consumption propensity coefficient $\beta \mathrm{i}$ is a set of indicators that reflect the propensity to consume after meeting basic consumer demand. It represents the proportion of the remaining monetary income used by the consumer for the consumption of the i-th commodity or labor after deducting the basic consumer demand expenditure. It shows the proportion of money in development and enjoyment consumption in a relative number. According to Table 1, it can be seen that: Firstly, the consumption focus of residents is shifted from communication consumption to cultural entertainment; secondly, the residents of Liaoning Province are spending less and less on communication tools, and on the other hand, the infrastructure of communication information in Liaoning Province has been basically improved. Thirdly, the most obvious change is the cultural and entertainment consumption. It shows that with the increase of residents' disposable income, the demand for information consumption of residents has risen from simple information products to higher level information services and contents. The requirements for information are becoming more and more strict, especially the richness of spiritual life. 


\section{2) Income elasticity analysis of consumer demand}

The marginal consumption propensity coefficient can examine consumer's spending behavior under certain income levels. However, when the income level changes, what kind of consumption decisions consumers may make, the income elasticity is needed to analyze. The so-called income elasticity refers to the corresponding change rate in demand due to changes in income under the condition of constant price. Transforming the extended linear expenditure system model, you can get the specific formula of the income elasticity coefficient:

$$
E_{i j}=\beta_{i} * Y / V
$$

The income elasticity coefficient can be used as an important indicator to determine the life consumption and other consumption. According to the previous information consumption expenditure model, the income elasticity of each information consumption can be calculated. Here, the 2016 disposable income is taken as the $\mathrm{Y}$ value to calculate the income elasticity. The elasticity coefficient is shown in Table 3.

TABLE III. URBAN RESIDENT S' INFORMATION CONSUMPTION ELASTICITY COEFFICIENT

\begin{tabular}{|c|c|c|c|}
\hline Time & $\begin{array}{c}\text { Communication } \\
\text { consumption }\end{array}$ & $\begin{array}{c}\text { Education } \\
\text { consumption }\end{array}$ & $\begin{array}{c}\text { Cultural and } \\
\text { entertainment } \\
\text { consumption }\end{array}$ \\
\hline $2007-2016$ & 0.78923686 & 0.88155434 & 1.00568537 \\
\hline
\end{tabular}

It can be seen from Table 3 that the elasticity coefficient of each information consumption category is in turn: communication consumption less than education consumption less then cultural entertainment consumption. On the one hand, it shows that for every 1 percentage point increase in disposable income, it almost can drive information consumption to increase by 0.8 percentage points. On the other hand, it shows that information consumption has gradually become a necessity in the production and life of urban residents. The highest coefficient of elasticity in the table is the demand for cultural and entertainment consumption. This shows that people are paying more and more attention to leisure travel services and their cultural literacy services will continue to increase after meeting basic living and information needs.

\section{EMPIRICAL ANALYSIS OF THE IMPACT OF INFORMATION} CONSUMPTION STRUCTURE ON INFORMATION INDUSTRY

According to the theory of Wang Hui [6], the information industry is defined as an emerging industry group specializing in the provision of information services, information technology research and development, and information equipment and device production in social economic activities, including software industry, information equipment manufacturing and communication industry, etc.

According to the annual statistical yearbook published by Liaoning Province, all industries in the province are divided into forty-two related industries, including communication equipment, computers and other electronic equipment manufacturing, information transmission, computer services and software industry, education industry, Culture, sports and entertainment. These four types of industrial values are extracted as: information equipment manufacturing, information service industry and information content industry, in which data of education and information transmission, computer services and software are merged into information service industry. The data analysis is based on the regional input-output tables of Liaoning Province in 2007 and 2012 issued by the Liaoning Bureau of Statistics.

\section{A. Influence coefficient}

From the data point of view, the influence coefficient refers to the quantity of production required by each department through direct and indirect correlation when a department adds the final demand of the unit. The specific meaning of the influence coefficient when using the input-output table is the degree of influence on all other economic sectors when adding one unit of output in any production sector. The greater the influence coefficient of the department, the bigger the pulling effect of the department on other departments. According to the input-output tables published by the Liaoning Bureau of Statistics in 2007 and 2012, the influence coefficient of information industry in Liaoning Province can be extracted, as shown in Table 4.

TABLE IV. INFLUENCE COEFFICIENT OF INFORMATION INDUSTRY

\begin{tabular}{|c|c|c|c|}
\hline Year & $\begin{array}{c}\text { information } \\
\text { equipment } \\
\text { manufacturing }\end{array}$ & $\begin{array}{c}\text { information } \\
\text { service industry }\end{array}$ & $\begin{array}{c}\text { information } \\
\text { content industry }\end{array}$ \\
\hline 2007 & 1.078409197 & 0.739626219 & 0.72080638 \\
\hline 2012 & 1.270607413 & 0.642542606 & 0.812954191 \\
\hline
\end{tabular}

It can be seen from Table 4 that first, the influence coefficient of information equipment manufacturing, information service industry and information content industry in Liaoning Province has increased in varying degrees, indicating that the scale of information industry is constantly increasing, while the influence of information industry is constantly improving. Secondly, it can be clearly found that the influence coefficient of information equipment manufacturing in Liaoning Province is greater than 1, far higher than the information service industry and the information content industry, because Liaoning Province is a major province of information industry, while the information industry in Liaoning Province is mainly based on electronic equipment manufacturing. The information equipment manufacturing has a significant role in promoting the economy of our province.

\section{B. Induction coefficient}

The specific meaning of the induction coefficient is the extent to which a sector of the national economy receives demand sensing for each additional unit that is eventually used. A large coefficient indicates that the department's demand for economic development is highly sensitive, and conversely, it indicates that the demand for economic development is weak.

According to Input-Output Table published by Liaoning Bureau of Statistics in 2007 and 2012, the induction coefficient of the information industry in Liaoning Province can be extracted, as shown in Table 5. 
TABLE V. INDUCTION OF INFORMATION INDUSTRY

\begin{tabular}{|c|c|c|c|}
\hline Year & $\begin{array}{c}\text { Information } \\
\text { equipment } \\
\text { manufacturing }\end{array}$ & $\begin{array}{c}\text { Information } \\
\text { service indus try }\end{array}$ & $\begin{array}{c}\text { Information } \\
\text { content industry }\end{array}$ \\
\hline 2007 & 0.930254063 & 0.516977018 & 0.421692111 \\
\hline 2012 & 0.997297678 & 0.576603866 & 0.498932199 \\
\hline
\end{tabular}

It can be seen from Table 5 that the induction coefficient of information equipment manufacturing is higher and the induction coefficients of information service industry and information content industry are lower than 1, indicating that when the industry increases the output of one unit, it provides less output to the entire national production industry. Compared with the information service industry and the information content industry, the information equipment manufacturing radiates more industries, and the entire secondary industry affects the information equipment manufacturing more or less.

In summary, from the perspective of information industry itself, the information equipment manufacturing industry far exceeds the information service industry and the information content industry in both the induction coefficient and the influence coefficient. The structure of the production sector in information equipment manufacturing determines the characteristics of industrial production. Compared with the other two information industries, it has a broader radiation sector. The difference in influence and induction of various departments also shows that the information industry in our province is mainly based on information equipment manufacturing, while the information service industry and information content industry account for a small proportion. Although the information industry in Liaoning Province is growing at a rapid rate, the structural adjustment of the information industry is also urgent.

\section{CONCLUSION}

Since the reform and opening up, the economic development of Liaoning Province has undergone tremendous changes, and the industrial structure has also changed with economic development. The information industry in Liaoning Province is mainly based on information manufacturing and supplemented by information service industry. Combined with the development status of information industry in Liaoning Province, the average growth rate of information service industry obviously exceeds that of information equipment manufacturing. Therefore, how to promote the development of information service industry will be the focus of Liaoning Province's future development and a new growth point of Liaoning's information industry. At the same time, the development of information consumption requires a good information environment. The development of information industry must be accompanied by a healthy rule of law environment. Therefore, it is recommended to strengthen the improvement of information industry laws and regulations. The government should pay more attention to the function construction of information management and strengthen the supervision of information services, online transactions and the quality of information products and the regulation of the information industry.

\section{REFERENCES}

[1] Zheng Li, "Research on Resident's Information Consumption and its Influence on Economic Growth and Industry Structure”, Master Degree Thesis,Beijing University of Posts and Telecommunications,2014(In Chinese)

[2] Zhu Xiaoming, "The Analysis of the Domestic Information Consumption Structure's Impact on the Industrial Structure”, Master Degree Thesis, Anhui University of Finance and Economics,2012(In Chinese)

[3] Zhang,Sihang. "Research on Information Consumption Coefficient's Calculating Methods and its Influence Factors”, Master Degree Thesis, Beijing University of Posts and Telecommunications,2015(In Chinese)

[4] Wu Fengwu, Hu zuquan. "The Measurement and Characteristic Analysis of the Information Consumption Scale of Urban Residents in China”, Journal of Commercial Economics, vol. 33, pp 44-45,2013(In Chinese)

[5] Han Wei, “Analysis of the Impact of Information Consumption Structure Changes of Residents in Jiangsu Province on Information Industry” , Master Degree Thesis, Heilongjiang University,2015(In Chinese)

[6] Wang hui, Cui Jie, Wang Shuqiao. "Research on the Relationship between Information Industry Development and Economic Growth in Jiangsu Province”, East China Economic Management, vol. 9, pp,1922,2014(In Chinese) 